\title{
A reforma educacional no México e no Chile: apontamentos sobre as rupturas e continuidades
}

\section{The education reform in Mexico and Chile: appointments on ruptures and continuities}

\author{
Nora Rut Krawczyk* \\ Vera Lúcia Vieira**
}

\begin{abstract}
RESUMO
Este artigo busca resgatar a inflexão ocorrida recentemente nas políticas educacionais da América Latina a partir de duas situações específicas, a do México e a do Chile. Considerando que tais políticas têm sido implementadas a partir de uma lógica relacionada à globalização capitalista em curso e são expressões da correlação de forças sociais num espaço concreto, propõe-se identificar de que forma diretrizes comuns, definidas por organismos internacionais, interagem com as características culturais vigentes em cada país. Tal preocupação advém da percepção acerca da função social da área educacional e de sua dinâmica como expressão das contradições. Conclui-se que, embora alvo de políticas semelhantes, a realidade educacional nos dois países expressa situações distintas: no México, tem-se uma "ruptura conservadora", pelo seu caráter regressivo, e no Chile uma "continuidade conservadora".

Palavras-chave: políticas educacionais, globalização, reformas educacionais na América Latina.
\end{abstract}

* Doutora em Educação pela Unicamp. Professora na Faculdade de Educação da Unicamp e no Programa de Pós-graduação em Educação: Currículo da PUC/SP. <norak@terra.com.br>

** Doutora em História pela PUC/SP. Professora no Programa de Pós-graduação em História e no Curso de Relações Internacionais da PUC/SP. <vevi@terra.com.br> 


\begin{abstract}
This article intends to rescue the inflection recently occurred on the education politics of Latin America, taking as starting point two specific situations: Mexico and Chile. It considers that such politics have been implemented since a logic related to capitalist globalization in course, whose are expressions of the correlation of social forces in a concrete space; This article intends to identify in which way common guidelines, defined by international organisms, interact with effective cultural characteristics of each country. Such preoccupation is product of the perception of social function of the education area and its dynamics as contradictions expression. It is ended that, although goal of similar politics, education reality in these two countries expresses different situations: in Mexico, there is a "conservative rupture", by its regressive character, and in Chile there is a "conservative continuity".

Key-words: education politics, globalization, education reforms in Latin America.
\end{abstract}

No âmbito educacional, as reformas realizadas nas últimas décadas, em grande parte dos países de diferentes continentes, são portadoras de pressupostos que derivam do paradigma de desenvolvimento capitalista contemporâneo. Elas foram concebidas no marco de um novo arranjo das relações de poder internacionais e da reconfiguração do modelo de Estado provedor e regulador para o de Estado forte e minimalista. ${ }^{1}$

Globalização $^{2}$ e descentralização são dois termos bastante encontrados nos estudos de ciências sociais e nas análises políticas durante a década de 90, nos diferentes países. São dois conceitos controvertidos porque expressam novas formas de organização, governo e regulação ${ }^{3}$ econômica, social e política. Esses conceitos resultam de marchas que consagram transformações estruturais e o avanço dos processos de diferenciação.

1 Minimalista em todos os investimentos sociais e nas intervenções econômicas, mas forte na sua capacidade para romper com o modelo estabelecido.

2 Globalização é esta aceleração das interdependências de todos os povos e países, em termos econômicos e socioculturais, que se consolida a partir da década de 80 , dado o vertiginoso crescimento dos principais centros nervosos das sociedades modernas, quais sejam: os mercados financeiros e as redes de informação. (CASTELLS, 2000)

3 O modelo de regulação na sociedade capitalista é a relação Estado-sociedade por meio da qual o próprio sistema mantém e controla os processos de diferenciação e exclusão dentro de certos limites. Por exemplo, o modelo social-democrata supõe uma forte regulamentação do capital pelo Estado, enquanto o modelo neoliberal supõe "a liberalização das forças do mercado" e a sua auto-regulação pela lógica da competitividade. 
De fato, a globalização contemporânea ${ }^{4}$ tem gerado uma nova ordem econômica internacional que sobrepõe os mercados às nações, vinculando os processos de integração e diferenciação à competitividade dos primeiros.

Esse duplo movimento de globalização e descentralização tem, sem dúvida, sua expressão na reforma educacional atual. Nessa perspectiva, sob a égide da democratização e integração internacional dos países latinoamericanos, foram adotados parâmetros de avaliação de seus sistemas educacionais que definiram as políticas dos organismos internacionais para a região.

Sabe-se que o processo de implementação das reformas educacionais das últimas décadas produz uma padronização das políticas na área, unificando um quadro de referência conceitual acerca das diferentes dimensões da problemática educativa e de suas prioridades e estratégias nacionais.

Implementadas, estas políticas têm se defrontado com a heterogeneidade própria de cada país, expressões de sua cultura, ou seja, de suas formas particulares de realização societária, na produção de seres sociais específicos. Acresce-se a isto a tradição autocrática inerente ao funcionamento dos Estados na região, de que resulta a implementação de políticas sempre de forma estranha a estas culturas, mesmo quando respondem às suas demandas sociais.

$\mathrm{Na}$ área educacional, esta lógica se evidencia com muita nitidez, dada a função social que compete a este setor cumprir no interior do Estado: sua dinâmica é a expressão das contradições sociais, e neste sentido reifica as culturas locais, cujo conjunto é a expressão da particularidade de cada país na região. A oportunidade de reflexões sobre estas questões, a partir de duas situações específicas, o México e o Chile, conforme propõe este artigo, surgiu da pesquisa sobre a produção científica existente em países latino-americanos, que é relativa a esta reforma educacional que se inicia na década de 90 na região. ${ }^{5}$

4 O processo de globalização, como vários autores já têm demonstrado, é uma tendência que acompanha o desenvolvimento do capitalismo, fazendo parte de sua lógica interna. A sua fase atual ou contemporânea, no entanto, tem certos distintivos, cuja compreensão é necessária.

5 Pesquisa interdisciplinar: O Estado da Arte das Pesquisas sobre a Reforma Educativa na Década de 1990 no Brasil, Argentina, Chile e México, financiada pela Fapesp. 
O século XX foi marcado, tanto no México como no Chile, pelo forte desenvolvimento do ensino fundamental, o que permitiu que se chegasse às vias da universalização deste nível de ensino. Esse processo se deu, no México, no marco da consolidação da revolução que resultou em um governo de coalizão, consubstanciado no PRI, que teve a educação como política de unidade nacional e reguladora das desigualdades sociais. No Chile, encontramos a mesma intencionalidade acompanhando a expansão do ensino fundamental, mas no marco de um processo histórico distinto. Embora tendo em comum o fato de o Estado manter-se altamente centralizador e regulador, no Chile o século XX se caracterizou pela democratização política crescente que desembocou no socialismo real de Allende, enquanto no México a coalizão não conseguiu ultrapassar a autocracia que foi a sua marca até a década de 80 .

A literatura sobre o tema destaca em ambos os países que a tradição altamente centralizadora do Estado não conseguiu, mesmo sob os auspícios da democratização, consolidar uma participação efetiva da população nas decisões políticas. Constituídos seus sistemas educacionais em fins do século XIX, como resultante dos processos de independência e consolidação do Estado nacional, pode-se adotar para os dois países as denominações desenvolvidas por NúÑEZ (2002): para o Chile, de que o século XX, no que diz respeito à educação, é um "siglo corto" no qual ocorre "la gesta de la expansión" e "la empresa del reformismo".

A partir da década de 80 , a perspectiva de inserção ou aprofundamento da globalização e do livre mercado se materializa, entre outras mudanças, na implementação de reformas sociais, dentre as quais se destacam as educacionais, com paradigmas bem distintos das anteriores, embora mantendo a mesma perspectiva acerca da função social que a educação deveria cumprir.

Nesta ótica, a conciliação entre a educação e o desenvolvimento econômico mantém-se como uma das peculiaridades mais enfatizadas das reformas ao longo do século XX. Por falta de outras iniciativas, a educação vai sendo cada vez mais energicamente colocada como o canal majoritário para a resolução dos problemas resultantes das desigualdades sociais, tanto os de ordem econômica - pela possibilidade de promover maior e melhor ingresso no mercado de trabalho - quanto pela garantia da eqüidade, ou seja, condições igualitárias de escolarização e qualidade do ensino, independentemente da condição socioeconômica.

Apesar desta unicidade das políticas educacionais vigentes nos países da região, observa-se uma inflexão que a diferencia, em conseqüência do 
embate entre as diretrizes e a concretude social vigorante em cada um deles. É sobre esta inflexão que este artigo busca refletir. Em outras palavras, busca-se identificar de que forma diretrizes comuns definidas por organismos internacionais e adotadas pelos governos mais recentes se chocam com as características culturais vigentes em cada região. Busca-se extrair, dos nexos constitutivos destas realidades sociais, aspectos comuns a serem analisados, consideradas realidades em sua posição relativa na ordem global a que pertencem e em face da correlação de forças internas que as engendram. No entanto, não há a intenção de analisar as novas realidades educacionais nacionais em sua concretude empírica, mas resgatá-las a partir das reflexões dos especialistas em sua produção institucional.

Decorrente destas políticas, os dois países adentram os anos 1980 bastante avançados em termos de inclusão educacional, ainda que os benefícios tenham sido singulares e diferenciados para suas populações, principalmente em relação à melhor qualidade atingida no Chile, em comparação com a do México.

A década de 80 se inicia sob os auspícios de uma crise econômica do capitalismo internacional que repercute na educação, com a redução de investimentos no setor. No México, tal restrição de recursos públicos significou a adoção de políticas sociais mais seletivas, com um enorme custo social (estima-se que, entre 1982 e 87, o gasto nacional em educação caiu de $5,5 \%$ para 3,6\% do PIB); no Chile pós-ditadura, esta redução reforçou posições pró-Pinochet, em cujo governo os investimentos educacionais haviam sido maiores, a ponto de o país ter atingido as metas de universalização do ensino básico já na década de 80 . Neste país, nos anos 70, investia-se por aluno o equivalente a $15 \%$ do produto interno per capita, proporção que havia baixado para $10 \%$ em $1990 .{ }^{6}$ Nos primeiros anos da década de 90 , entretanto, os investimentos em educação nos dois países voltaram a crescer.

De uma forma ou de outra, as reformas que se iniciam nesta época ocorrem sob a lógica da "modernização", seguindo a tendência de toda a região, que buscava adaptar a educação às mudanças econômicas e de concorrência internacional. Neste sentido, propõem-se a inovar não só as relações institucionais no interior do próprio Estado, que se mantém na liderança da implementação das reformas, mas também as parcerias com a sociedade civil. 
Assim é que, no México, vários estudos indicam que foi no governo de Carlos Salinas de Gortari (1988-94) que se começou a impulsionar com maior intensidade (no âmbito educacional) uma lógica política bastante diferente daquela que foi característica desde a Revolução Mexicana; lógica que vai ter implicações substantivas no Acuerdo Nacional para la Modernización de la Educación Básica - ANMEB, assinado em maio de 1992 entre o governo da República, as administrações das 31 entidades federativas e o Sindicato Nacional de Trabalhadores da Educação - SNTE. Este pacto deu lugar, um ano mais tarde, à promulgação da nova Lei Geral de Educação e foi a base para a reforma educacional posterior.

A assinatura desse acordo significou uma ruptura na história do país e a culminação de um longo e difícil processo de negociação entre os atores envolvidos. O ANMEB inaugurou uma política de modernização da educação básica em duas direções: uma reforma educativa e uma político-administrativa. Com essa determinação se dava início a um processo de descentralização dos principais serviços educacionais prestados pela Secretaria de Educação Pública - SEP, conhecido como federalização.

No caso do México, a educação básica parece ser um pouco mais resistente à privatização e este processo de "modernização" deu-se mais cedo no âmbito da educação superior, devido às condições impostas pelo Tratado de Livre Comércio - TLC. Este, que reúne Canadá, EUA e México, foi assinado em 1994, tendo sido precedido de um período de debate, preparação e comparações da situação dos países membros. Neste sentido, em 1991 um grupo de pesquisadores reuniu-se para analisar e discutir os temas da educação e da cultura em face do TLC, centrado em saber se a educação mexicana estava em condições de preparar a população para o ingresso no mercado internacional e que mudanças poderiam sofrer a educação e a cultura a partir da abertura econômica.

No Chile, o antecedente imediato dessa reforma educacional, iniciada em 1996, foi a criação, no final de 1994, de uma Comisión Nacional para la Modernización de la Educación, convocada pelo presidente da República, que avaliou a reforma como um "imperativo histórico". As propostas que conformarão esta reforma, no entanto, não serão novas - pelo contrário, em que pese o "imperativo histórico", os projetos implantados encontram seus referenciais ainda na década de 80; esta continuidade lhes possibilita, já nos primeiros anos da década de 90 , introduzir projetos como os Programas Mece Básico e o P-900 Escolas, sobre os quais se falará mais adiante. Isto sem considerar que o projeto de subvenção, outro pilar desta 
reforma, encontra sua gênese na própria constituição do sistema de ensino chileno, em fins do século XIX.

De qualquer forma, diferentemente do que se observa em outros países, os eixos da reforma no Chile vêm sendo delineados, pelo menos legalmente, ${ }^{7}$ de forma muito integrada, tendo como principal vetor o sistema de subvenção.

\section{A descentralização enquanto paradigma da reforma educacional}

A descentralização do sistema educacional, dependendo do país, não significou apenas a transferência de parcelas do sistema das administrações mais centrais para as regionais - isto é, diretamente vinculadas ao poder local em sua última instância -, mas também o deslocamento de parte do gerenciamento das unidades do sistema para elas mesmas, em colaboração com a comunidade local. Para TAPIA (1999), a descentralização educacional está vinculada às grandes crises políticas dos Estados, à forte decadência educacional em termos de qualidade e eqüidade, a uma baixa substancial nos recursos destinados à educação, a uma pressão das instituições no sentido de granjear maior autonomia política e administrativa e, sobretudo, à grande coação dos organismos internacionais (FMI, Banco Mundial e Banco Interamericano de Desenvolvimento) que, como salienta, financiam as políticas descentralizadoras, com o objetivo de alcançar paulatinamente um melhor ajuste fiscal.

No México, o Acuerdo Nacional para la Modernización de la Educación Básica estabeleceu, entre outras providências, a transferência das unidades de educação pré-escolar, primária, secundária e normal, que estavam sob controle do governo federal, aos respectivos governos estaduais. Empreendida na década de 90, esta descentralização, denominada

7 Pesquisadores vêm observando dicotomias entre as proposituras da lei e a realidade cotidiana da rede, contestando a plena consecução dos preceitos legais. (VILLEGAS, 1999; GÓMEZ, 2001). 
federalização ${ }^{8}$ educacional, constitui uma das mudanças mais importantes na organização do sistema educacional mexicano do século XX. Foram transferidas 68.932 escolas primárias e 9.436 escolas secundárias, ficando os Estados responsáveis pela sua administração, pela reformulação curricular e pela capacitação dos professores. O governo central, no entanto, reteve uma série de funções normativas, avaliativas e compensatórias que, de fato, permitiram-lhe exercer um forte controle sobre o sistema.

É inegável a relevância que o debate educacional mexicano outorga ao processo de descentralização enquanto elemento-chave de uma nova conceitualização da educação no país, o que pode ser explicado, em primeira instância, pela importância social e política que assume a ruptura com o projeto federalista centralizado do PRI.

Os estudos sobre o tema nos permitem perceber que não há consenso quanto ao alcance do processo de federalização, ainda que esteja claro que não foi homogêneo em todos os Estados do país. Várias pesquisas indicam que, além da história e das condições específicas de cada um dos Estados, o rumo da federalização em cada situação obedeceu, entre outros fatores, à especial interação entre as burocracias estatais e sindicais. Também indicam esses estudos que o processo de descentralização vem produzindo conflitos entre o governo federal e os estaduais em torno de problemas referentes a condições de trabalho, de currículo e, principalmente, financiamento.

Nesse sentido, TATTO (1999) afirma que a reforma educacional mexicana não pode ser classificada como descentralizadora stricto sensu. Ao contrário, o governo federal reteve para si o controle dos recursos financeiros - que são apenas repassados para os estados - e das funções curriculares, deixando para as administrações estaduais apenas a administração local e alguma possibilidade de desenvolvimento de um currículo regional. A autora atribui parte da resistência em delegar responsabilidades aos estados à dificuldade do governo federal de aceitar, de fato, o poder de grupos políticos adversários.

Pode-se fazer considerações similares para o Chile, em que pese sua especificidade. Os analistas neste país têm apontado conflitos entre o governo central, os municípios e as unidades escolares no processo de descentralização, que se expressam nas reclamações das escolas e/ou das

8 A escolha do termo federalização em vez de descentralização, durante a negociação do ANMEB, deveu-se ao desejo de transmitir a idéia de um acordo político que encontrasse sustentação no regime federalista estabelecido na Constituição, e não caracterizar como meramente administrativa a política em curso. 
municipalidades por ficarem isoladas do processo decisório, em decorrência da forma como o Plano Anual de Desenvolvimento Educacional Municipal - Padem tramita. Queixam-se, também, que o governo central ainda define a organização curricular - não havendo espaço para o tratamento de características locais - e que os recursos financeiros e "subvenções" variam muito, pois estão condicionados ao desempenho da escola.

Acresce-se a isto que, no Chile, a descentralização adquire contornos mais complexos, ${ }^{9}$ resultando em uma ressignificação do público. Este processo se dá por meio da transferência de escolas públicas para o gerenciamento da iniciativa privada, pela abertura de escolas particulares visando a garantir o atendimento à demanda e pela subvenção às escolas particulares.

Este processo envolve parcerias dos governos central e municipais com a iniciativa privada e com os pais e apoderados, ${ }^{10}$ de que resultam três tipos de gestão, ${ }^{11}$ conforme a dependência: a exclusivamente municipal, que não é necessariamente gratuita; a privada subsidiada (com financiamento do Estado e participação da administração privada) e, por fim, o sistema privado, que se pauta unicamente na administração privada ${ }^{12}$ (BRAVO, 1999). Não por acaso, no Chile a descentralização é entendida nos estudos acadêmicos como a transferência efetiva de competências, ${ }^{13}$ decisões e recursos para um organismo exterior e autônomo do sistema estatal centralizado (TAPIA, 1999).

9 Segundo a Constituição de 1980, o Chile é um país unitário dividido em regiões, e sua administração será funcional ou administrativamente descentralizada ou desconcentrada, em conformidade com a lei.

10 Trata-se de pessoa ou representante que assume a responsabilidade por encargos educacionais, seja nas unidades escolares, seja nas instâncias intermediárias do sistema educacional. Tais encargos podem ser de diversas ordens: financeiros, participação em conselhos e até mesmo de direção.

11 Não estamos considerando o ensino profissionalizante, por não ser objeto desta pesquisa, que caracteriza um quarto tipo de gestão: o das subvencionadas pelas corporações empresariais (GONZÁLEZ, 2001).

12 A proporção na distribuição destas unidades no Chile é a seguinte: em 1999, existiam 10.605 estabelecimentos escolares particulares subvencionados e particulares e de administração delegada, com aproximadamente 18.160 unidades educativas. Considerando um total de 3.508.509 alunos matriculados, cerca de 54\% estavam em escolas municipalizadas, $34 \%$ em particulares subvencionadas, $9 \%$ em particulares e $2 \%$ em administração delegada. (MINEDUC, 2001).

13 Do ponto de vista legal, a descentralização no Chile se concretiza com a organização de "13 Secretarías Regionales de Educación y luego, en 1981, se traspasaron los servicios educativos a las municipalidades y a los privados”. (GÓMEZ, 2001) 
Tanto no México quanto no Chile destacam-se os conflitos entre o governo federal e os estaduais em torno de problemas referentes às condições materiais e, principalmente, de financiamento no processo de descentralização.

\section{A redefinição do financiamento público}

A nova lógica que orienta as políticas educacionais de cada país tem delineado na última década também novos rumos da ação política para a educação básica que reduzem a presença do Estado e passam a priorizar o caráter compensatório dos programas governamentais, deixando clara a preferência pelas estratégias de focalização nos grupos de extrema pobreza.

Assim, no México, nos últimos anos o mais importante investimento educacional do governo federal tem se concentrado principalmente na implementação de programas compensatórios que, na atualidade, abarcam todos os Estados do país. ${ }^{14}$ Esta tendência de comportamento do governo federal está legitimada pelas competências que lhe são definidas na Lei Geral de Educação.

Antes das reformas da década de 90, no entanto, já existiam no México programas federais que, objetivando melhorar a eqüidade educacional, criaram subsistemas paralelos para poder estender a cobertura nas zonas rurais por meio de desenhos alternativos, como, por exemplo, os cursos comunitários do Conafe, que operam desde 1973 e cobrem atualmente $1 \%$ da matrícula primária, e a Telesecundária, que se iniciou em 1966 e representa hoje $10 \%$ das matrículas no nível. Existem muitos estudos e avaliações desses projetos; no entanto, aparentemente, não foram levados em conta na elaboração e implementação dos novos programas compensatórios.

No Chile os programas são do mesmo teor e visam a interferir particularmente na questão da equalização, tanto na zona urbana quanto na rural. O mais tradicional destes programas é o destinado ao incentivo edu-

14 Entre os projetos educacionais mais importantes no México, destacam-se o Programa para Abatir el Rezago Educativo (Pare) e o Programa de Educación, Salud y Alimentación (Progresa). 
cacional às escolas mais pobres, sejam rurais ou urbanas, denominado Programa $P$-900 Escolas. ${ }^{15} \mathrm{O}$ programa se propõe a dar apoio a $10 \%$ das instituições com pior rendimento e maiores necessidades e aos alunos de primeiro ciclo (até quatro anos), para que sejam alfabetizados. ${ }^{16}$ Já para a zona rural vem sendo implantado o Mece Rural, também com o intuito de subsidiar estas escolas com equipamentos, infra-estrutura e formação de docentes, visando a uma atuação mais adequada à realidade das crianças. ${ }^{17}$

15 Sobre os resultados práticos do $P-900$, o Cieplan, tendo também em conta as cifras do Simce, afirma que, no primeiro período do programa, entre 1988 e 92, todas as variantes selecionadas e avaliadas foram positivas (de $0,80 \mathrm{em} 1988$ para 3,56 pontos em 1992). Conforme os dados do Cieplan, os efeitos do $P-900$ são mais positivos e mais altos em escolas que têm entre 100 e 300 alunos. Todavia, os órgãos que possuem a incumbência da avaliação do $P-900$ reconhecem que a metodologia tem de ser mais bem formulada a fim de que expresse melhor a realidade. Conforme o autor, os programas voltados para grupos desfavorecidos, tal como o $P$-900, exercem um papel importante na consolidação da eqüidade e da qualidade do ensino. (YEPES, 2000).

16 Conforme dados do Mineduc, até o ano de 2001 participavam desta prioridade 2.361 estabelecimentos com mais de meio milhão de alunos, quase 20 mil docentes e 15 mil jovens monitores. O custo total por aluno é de US\$20. Além disso, propõe-se equipar as instituições com bibliotecas e livros, com inovações em infra-estrutura e materiais didáticos, além da instalação de computadores nas escolas marginais e rurais. No ano 2000, conforme dados oficiais, metade destas escolas, justamente as que concentram a maior parte das matrículas, possuía laboratório de informática e 5.200 estabelecimentos contavam com acesso gratuito à internet. Neste programa incluem-se escolas rurais, que constituem cerca de 3.000 unidades incompletas, pequenas e dispersas, que escolarizam até o sexto ano básico em cursos multigraduados. No entanto, dados do CIDE (2001) indicam que "Las diferencias en equipamiento conputacional se manifiestan fuertemente entre los distintos tipos de establecimientos. En los colegios municipalizados el 50\% de los docentes estiman que es insuficiente la cantidad de conputadores, mientras que en los colegios particulares lo hace el $9 \%$, estableciendo una diferencia de más de cinco veces. Los colegios particulares subvencionados se sitúan en un nivel intermedio" (CIDE, 2001, p. 60).

17 Gajardo, na Revista do Mineduc, considera que, desde 1990, com a implementação do P-900 e do Programa Mece, as escolas rurais vêm tornando-se mais adequadas por introduzirem novos recursos, tais como textos específicos para o ensino rural; abertura de bibliotecas; aperfeiçoamento de docentes (com vocação e interesse) para adequarem conteúdos à realidade dos educandos, entre outros. Seus estudos constataram que, dada a importância do docente para a melhoria do processo educacional: 1) os melhores professores são aqueles que trabalham e vivem no mesmo local. Esses usam o material que recebem, são mais dedicados, criativos e estão integrados à comunidade escolar. 2) os docentes que têm mais de dez anos no magistério e mais idade são os que obtêm melhores resultados com os estudantes. A fim de adaptar melhor o currículo escolar, Gajardo está convencida de que falta conhecimento a respeito da interação escola-comunidade, ou seja: conhecimento sobre diversidades regionais - além da rural e urbana; tipos de família e atividades agrícolas. 
O que se observa, mais uma vez, é a similitude entre os programas desenvolvidos por dois países com culturas tão distintas, mas cujos problemas educacionais, em conseqüência das disparidades socioeconômicas, são tão semelhantes.

\section{Gestão escolar}

No bojo da descentralização, situam-se os problemas relativos à adaptação da gestão da escola que, a nosso ver, não pode ser analisada em separado da reformulação do funcionamento do próprio Estado; este, em sua ótica neoliberal, preconiza a minimização de suas responsabilidades sociais e a transmuta em "parceria" com a sociedade civil no atendimento às demandas da população. Significa também inovar normas e procedimentos e enxugar a burocracia, com o objetivo de obter maior racionalidade e funcionalidade nos trâmites e processos decisórios. Neste sentido, no início da reforma, no México e no Chile havia projetos de transformação da gestão escolar, tendo como novo desafio gerar uma forma de trabalho coletivo que rompesse com a velha prática profissional de trabalho como assunto absolutamente privado de cada professor. Para isso, consideravase necessário não só prestar atenção na rotina institucional das unidades escolares, como também revisar o regulamento que regia o trabalho cotidiano das escolas.

No México, no marco dos debates que levaram ao acordo em 1992, colocou-se a necessidade de transformar o funcionamento da escola porque havia consenso de que a autoridade (federal e estadual) tinha-se distanciado cada vez mais da instituição, em decorrência da centralização do sistema, afetando a organização escolar com excessos de mecanismos burocráticos e com a falta de possibilidade de compartilhar a responsabilidade da educação das crianças com sua família e com a comunidade. Assim, entre as ações prioritárias foi definido, também, o estabelecimento de um programa de reformas da organização e avaliação da escola.

A professora Justa Ezpeleta afirma ${ }^{18}$ que a qualidade na educação e a

18 Em entrevista que nos foi concedida em março de 2002, no México. 
necessidade de melhorar a aprendizagem dos alunos não é um tema novo entre as preocupações educacionais no México, mas sempre se circunscreveu às propostas de mudanças no trabalho pedagógico, apontando principalmente as formas de ensinar e os conteúdos. O projeto de transformação da gestão escolar que começou a ser implementado pela SEP em 1997 ampliou seu espectro para incluir a organização e a administração do nível básico como elemento interveniente na produção do ensino. Na realidade, este projeto significava pensar uma forma inovadora de capacitação de professores, que envolvesse a organização institucional e de todo o sistema educativo - governos estaduais e organismos intermediários.

A construção de um novo estilo de trabalho a partir de uma proposta pedagógica de gestão - isto é, que possibilitasse a melhoria do ensino significava, entre outras coisas, uma ruptura importante com práticas clientelistas e cooperativistas consolidadas na gestão educacional mexicana. Por exemplo, os principais quadros do Sindicato Nacional de Trabalhadores da Educação - SNTE são parte do aparelho administrativo da educação (situação que permaneceu mesmo com a queda do PRI), chegando ao ponto de haver confusão, nos níveis intermediários do sistema educativo, acerca do que é âmbito da representação sindical e do que é esfera da administração educativa.

Os responsáveis por este projeto têm a impressão de que ele está num processo de extinção, porque em seu lugar está sendo implementado o Programa de Escuelas de Calidad - PEC, que parece ser o carro-chefe do atual governo.

O PEC segue a tendência regional de considerar a gestão escolar exclusivamente em sua dimensão administrativa e de recuperar a competitividade da gestão de recursos materiais das equipes escolares. Apropria-se de uma forma de trabalho coletivo de elaboração de planos institucionais, mas muda-se seu sentido e intencionalidade.

Enquanto o projeto de transformação da gestão buscava elaborar coletivamente uma proposta para a escola que permitisse devolver a cada um dos atores envolvidos o sentido de suas tarefas com os alunos e gerar uma unidade escolar com identidade própria, o PEC se apossava da idéia do projeto escolar, mas o despojava de sua ambição de ser um processo de aprendizagem institucional, transformando-o numa ação de competição por recursos materiais entre as escolas.

O PEC em muito se assemelha ao Plano Anual de Desenvolvimento Educacional Municipal - Padem chileno, inclusive em suas conseqüênci- 
as. A especificidade do Padem, que foi implantado em 1993 no Chile, é o fato de envolver as municipalidades, por meio de corporações municipais, nas propostas de desenvolvimento educacional, a partir da consolidação dos planos de cada unidade escolar. O Padem deve partir de um diagnóstico de cada estabelecimento, contendo todas as informações sobre os aspectos acadêmicos, extracurriculares e administrativos. Além disso, a lei decreta que o Padem tomará para si a responsabilidade do projeto educacional de cada escola, formulando os objetivos educacionais a serem alcançados em cada instituição, e adequará as normas técnico-pedagógicas elaboradas pelo Mineduc a cada instituição.

Os Padem necessitam ser avaliados anualmente para dar lugar a novos programas de trabalho para o próximo ano. Pelo tempo de planejamento e por razões associadas à cultura institucional do setor municipal da educação, no entanto, seu processo de avaliação tem pouca importância, já que se limita a dar os resultados finais, sem permitir manifestações contínuas daqueles que administram estes programas (NAVARRO, 2000). Por outro lado, nem sempre as municipalidades consideram prioritário investir na educação conforme os planos indicam.

Mais uma vez, observa-se que a mesma diretriz adquire contornos distintos conforme as particularidades do Estado e a orientação do debate educacional em cada um dos países. No México se priorizou, no início da reforma, a construção de um novo estilo de trabalho a partir de uma proposta pedagógica de gestão que significasse, entre outras coisas, uma ruptura importante com práticas clientelistas e cooperativistas consolidadas na gestão educacional mexicana; diferentemente, no Chile o acesso dos profissionais ao sistema educacional já há muito se efetiva via processos seletivos cujos resultados são publicamente divulgados.

Pôde-se observar que, no México, o sistema de educação é coagulado de quadros do sindicato da área. Tal correlação de forças não ocorre no Chile que, com a diversificação de suas redes, descentralizou também os processos seletivos. Como o recebimento do subsídio está diretamente vinculado ao desempenho do aluno, por sua vez atrelado à avaliação do professor, as escolas tendem a ter critérios muito objetivos para a captação de seus profissionais.

No México não há ainda estudos que analisem as mudanças no interior das escolas, resultantes das políticas de descentralização, devido, entre outras coisas, a seu caráter incipiente e pouco consensual. Em contrapartida, no Chile o processo de descentralização, iniciado ainda na ditadura Pinochet, 
já permite inúmeras análises. Os questionamentos dos especialistas vão no sentido de que a descentralização, principalmente via "financiamento compartilhado", não só não rompeu com a segmentação do sistema educacional, como acentuou a diferença entre o grupo das escolas pobres com menor qualidade e o das escolas ricas com maior qualidade. ${ }^{19}$ Acresce-se a isto que o salário dos professores também varia conforme o desempenho de sua escola; assim, professores mais bem qualificados e mais atualizados buscam escolas em que há possibilidade de seu desempenho ser reconhecido pelos sistemas de avaliação e, portanto, de serem mais bem remunerados.

Em que pesem tais diferenças, é importante lembrar que tanto o PEC quanto o Padem compõem a mesma diretriz de gestão escolar no âmbito de um modelo de descentralização que busca diminuir o ônus da máquina administrativa e minimizar a ação social do Estado, transferindo competências à iniciativa privada e subordinando os fins educacionais à lógica do mercado. No México, em particular, isso significou uma ruptura com uma tendência educacional que já vinha sendo gerada no âmbito acadêmico e estava em vias de ser institucionalizada pelo governo. No Chile, por sua vez, isso representou a continuidade do processo de reforma liberal iniciada na época da ditadura de Pinochet.

19 O financiamento compartilhado é a parceria entre os recursos do governo central (Ministério da Educação), iniciativa privada e/ou apoderados e os recursos advindos da municipalidade. A transferência dos recursos do Mineduc para as unidades escolares se dá na forma de subsídios, mediante a apresentação do Padem; o montante é definido conforme o desempenho dos alunos. É aí que se evidencia o círculo vicioso. As escolas sediadas nos municípios mais pobres que, em geral, têm mais problemas estruturais de outras ordens a resolver na comunidade, recebem menos recursos da municipalidade. Além disso, sendo mais pobres, investem menos recursos e suas crianças e jovens têm menos acesso a informações e outros requisitos. Ou seja, sendo desempenho baixo, recebem menos subsídios governamentais. 


\section{Reforma educacional e conflito docente}

O acompanhamento, controle e avaliação da reforma consolidou-se em sistemas que vêm gerando uma tensão permanente entre governo e educadores. Esses sistemas têm por objetivo medir o desempenho das políticas implantadas e servir de parâmetro para erradicar pontos de estrangulamento de diversas ordens. Além disso, não deveriam se restringir aos canais burocráticos do governo, mas ser ampliados, contando com a participação de segmentos sociais direta ou indiretamente envolvidos com a educação.

Sobre este aspecto, as pesquisas indicam que em ambos os países a política de descentralização reforça as funções normativas e de avaliação do poder central; ao mesmo tempo, visa a propiciar, mediante a participação dos diferentes segmentos sociais, o avanço da reforma. Ainda que estejamos diante de uma mesma tendência nos dois países, é importante destacar que no México a busca do consenso incorpora setores tradicionalmente isolados das políticas públicas para educação, como é o caso da Igreja. ${ }^{20}$

O sistema de controle e avaliação estatal no México é um tema ainda não resolvido devido à forte oposição sindical. Em contraposição, os sistemas de avaliação no Chile já vêm de longa data e foram se aperfeiçoando no decorrer dos anos. ${ }^{21}$ Tais sistemas são os sustentáculos dos parâmetros

20 Na década de 1980 houve um processo de reaproximação do PRI com a Igreja, que se expressou, entre outros aspectos, na fixação na Constituição do país de que a educação básica ofertada pelo Estado continuaria sendo laica, mas os estabelecimentos particulares ganhavam liberdade para oferecer educação religiosa. Ainda que em curto prazo esta mudança constitucional tenha deixado a Igreja bastante satisfeita, o tema não ficou resolvido entre os diferentes setores da sociedade mexicana. Existem os grupos que gostariam que houvesse espaço para a educação religiosa na rede pública, mas também existem os que desconfiam dessa aproximação com a Igreja Católica e desejariam que se mantivesse o caráter laico da escola pública e privada. Este debate tem levado à discussão dos valores da educação pública e do sentido de uma educação moral, entre outros.

21 No interior da burocracia estatal existem basicamente três: o Simce - Sistema de Medición de la Calidad de la Educación, que detecta se o estabelecimento é de alto ou baixo nível acadêmico; o Cieplan - Corporación de Investigaciones Económicas para Latinoamérica, que está integrado aos parâmetros internacionais de avaliação, e o SND Sistema Nacional de Evaluación del Desempeño, que mede a performance dos professores. O Simce se aplica em todos os estabelecimentos dos três sistemas de ensino, incluindo as escolas do programa de compensação P-900. Já o Cieplan levanta os dados a partir de uma escolha aleatória das escolas, mas na amostragem as unidades que integram o $P$-900 não entram. Além disso, há o incentivo à avaliação da reforma pelos conselhos de pais e apoderados, sobre o que falaremos a seguir. 
das subvenções, já que fornecem as informações para a fixação do repasse em termos tanto do número de alunos e das gratificações dos professores quanto da inclusão ou não da escola nos programas compensatórios.

O Sistema Nacional de Evaluación del Desempeño - SND consiste na forma encontrada pelo Ministério da Educação chileno de, a partir de 1996, quantificar e avaliar os resultados do processo educacional no país visando a dar incentivo monetário aos docentes pelo seu bom desempenho profissional. O critério de escolha destes professores é único, ou seja, segue apenas os bons resultados acadêmicos de seus alunos, o que, por sua vez, é extraído das provas anuais de matemática e castelhano realizadas pelo Simce. A gratificação docente somente se consolida na medida em que o estabelecimento em que se leciona obtém bons resultados nas provas organizadas segundo estes preceitos. Seria importante salientar que o sistema de avaliação de desempenho não se concentra apenas na figura do docente, mas se estende também aos estabelecimentos educacionais, e os critérios de bonificação são os mesmos apresentados em relação aos professores. ${ }^{22}$

O incentivo ao professor, atrelado ao seu desempenho, também está presente entre as "inovações" produzidas nas condições de trabalho dos docentes mexicanos. Uma mudança importante na orientação política educacional da última década nesse país deu-se em relação ao estatuto docente. O ANMEB assinado em 1992 contempla, entre outras medidas, um Programa de Carrera Magisterial para elevar a qualidade profissional do trabalho docente e seus salários. Este programa prevê a implementação de um sistema de promoção que associa o salário com o desempenho docente e o aproveitamento escolar que obtêm os alunos.

Segundo vários pesquisadores da área, a concepção deste programa significa que a imagem do professor enquanto agente de mudança social, identificado com as metas da Revolução Mexicana, foi abandonada e substituída pela de um profissional com desejo de superação pessoal, que deve realizar com a maior eficiência possível o trabalho que lhe foi encomendado.

22 Conforme mizala (2000), pesquisa realizada pelo Ministério da Educação mostra que as gratificações têm aumentado consideravelmente nos últimos anos. Segundo o Ministério da Educação chileno, o número de professores contemplados pelo SND cresceu de 30.600 (na virada de 1996-97) para 32.600 em 2001-02. Já no que tange os estabelecimentos, o SNED chegou a contemplar 2.274 escolas de 1996 para 1997, o que demonstra a eficácia da experiência deste sistema de avaliação. 
Outros estudos indicam, ainda, que esse sistema de promoção aumenta o grau de competitividade e individualismo entre os professores, gera insegurança pela imposição de critérios de avaliação novos e externos à escola e diminui a autonomia sobre seu próprio trabalho.

$\mathrm{Na}$ atualidade, quase $80 \%$ dos docentes estão incorporados ao Programa de Carrera Magisterial, mas essa rápida inserção da maioria dos professores se deve, segundo os estudos, a que esse programa é, de fato, um mecanismo de controle e regulação das demandas econômicas e de promoção social dos interessados.

No México, com o processo de federalização/descentralização, o ANMEB introduziu novos procedimentos de negociação trabalhista, nos quais os governos estaduais substituíram o federal na relação com os trabalhadores da educação e, por sua parte, o SNTE delegou aos comitês executivos das seções de cada um dos estados as faculdades de representação nos assuntos vinculados à negociação salarial e outras condições de trabalho. Esta transferência de negociação para o âmbito estadual e municipal também ocorreu no Chile, embora de forma diversa, pois quem assumiu foi o próprio Estado. Um marco nesta diferença está na força que tais sindicatos possuem em cada um destes países.

Historicamente, no México as negociações salariais dos docentes de educação básica sempre se deram entre o sindicato de professores e a Secretaria de Educação Pública do governo central; além disso, os acordos eram estendidos também aos docentes que dependiam das administrações estaduais. Assim é que nesse país, ainda que numa primeira instância a transferência possa parecer uma ruptura e fragilização do sindicato docente, na realidade os governos estaduais negociam com o mesmo ator: o SNTE. Esta situação é, segundo os entrevistados na pesquisa, uma das expressões da força do sindicato nas negociações e conclusões do acordo.

No México este tema é de importância fundamental para o SNTE no processo de construção da sustentabilidade política de uma reforma educacional. Ele aparece no discurso acadêmico e político quase como um ator onipresente. Alberto Arnaut ${ }^{23}$ explica que a burocracia sindical teve historicamente, junto com o Estado nacional, o controle e co-administração do sistema educativo. O SNTE, na qualidade de sindicato único que agrupa os trabalhadores da secretaria de educação pública, na sua maior parte docentes, foi criado em 1944. Este sindicato deu, ao longo de várias décadas,

\section{ARNAUT, 1996.}


estabilidade no trabalho docente e outras garantias gremiais, mas ao mesmo tempo foi se constituindo num sério obstáculo à autonomia sindical, política e profissional dos docentes.

Já no Chile a participação do Colégio de Professores junto ao Estado é bem mais recente, integrando-se ao governo da Consertación que se formou após a ditadura de Pinochet. Atualmente, este atua com o governo, embora de forma crítica, fundamentalmente no aperfeiçoamento de professores, dados os incentivos governamentais para tanto. Seus integrantes questionam a diversidade salarial e constatam que divide a categoria, pois os professores que têm maiores salários e estão nas melhores escolas encontram-se satisfeitos, enquanto os insatisfeitos se concentram nas escolas municipalizadas das cidades mais pobres. Além disso, a diversidade salarial e de interesses dos docentes fragiliza a atuação do sindicato.

Esta fragilidade não se origina apenas no processo de reforma iniciado na década de 1990: está também diretamente vinculada à reorganização das forças políticas após o regime de Pinochet. Ainda durante a repressão, os exilados da coalizão comunista/socialista, em contato com a social-democracia internacional, à semelhança do que ocorreu em outros países nas mesmas circunstâncias, caminharam na direção do neoliberalismo. Como resultado, após a retomada do processo democrático, o eixo de esquerda foi substituído por uma coalizão dos socialistas com a Democracia Cristã, o que resultou no isolamento do Partido Comunista e o enfraquecimento das forças de esquerda, afetadas também pela crise de identidade das esquerdas internacionais, ocasionando sua divisão e a perda da capacidade de intervenção nacional.

O doutor Arnaut, especialista da área educacional no México, fazendo uma comparação com a situação de outros países, diz que, nas nações onde os professores foram sempre excluídos dos processos de decisão política, a construção do consenso com o grêmio ganha uma conotação positiva, mas no México, onde a burocracia sindical teve junto com o Estado o monopólio das decisões sobre o sistema educativo nacional, a necessidade de um consenso torna-se um tema bastante controvertido. ${ }^{24}$

$* * *$

24 Numa entrevista realizada em março de 2002, no México. 
As características que vai tomando a governação ${ }^{25}$ da educação por meio das políticas de descentralização e gestão são expressões da correlação de forças da sociedade num espaço concreto. Não cabe em um artigo realizar uma análise acabada da relação entre as tendências universais e particulares do processo da reforma educacional no Chile e no México, e por isso optou-se por apontar os aspectos que são relevantes pela sua conflitividade.

No decorrer das reflexões aqui desenvolvidas, evidencia-se, a cada passo, a impossibilidade de compreender a reforma educacional na América Latina, de suas rupturas e continuidades, sem discutir a historicidade da consolidação dos Estados nacionais, as condições de desenvolvimento e a posição relativa que a educação assume nesse contexto, sob pena de incorrermos na mesma lógica de imposição das reformas para a região.

O que se observa preliminarmente é que a processualidade histórica que caracteriza a realidade educacional nestes dois países da região vem sofrendo, no México, o que poderíamos denominar de "ruptura conservadora", pelo seu caráter regressivo, e no Chile uma "continuidade conservadora". Ambas decorrentes de imposições da ordem globalizada, tanto por pressões internacionais quanto por hegemonias nacionais.

\section{REFERÊNCIAS}

ARNAUT, A. Historia de una profesión. Los maestros de educación primaria en México 1887-1994. México: CIDE DF, 1996.

. La federalización educativa en México. Historia del debate sobre la centralización y la descentralización educativa (1889-1994). México: El Colegio de México, 1998.

ÁVILA, N. I. V. La federalización de la educación básica y el Sindicato Nacional de Trabajadores de la Educación en Guanajuato y Taxclala: un estudio comparativo. México, 1998. Dissertação (Mestrado) - Instituto de Invesitgaciones Dr. José María L. Mora.

BRAVO, D. et al. Rendimiento educacional, desigualdad y brecha de desempeño privado y publico. Chile 1982-1997. Santiago: Faculdad de Ciências Económicas y Administrativas, Universidad de Chile, 1999.

25 Ação social de governar. 
CARABANTES, W. C. Realidad y perspectivas de los planes anuales de desarrollo educativo municipales. Cartagena: [c/autor: editora?], mar./abr. 1996.

CASTELLS, M. A sociedade em rede. A era da informação: economia, sociedade e cultura São Paulo: Paz e Terra, v. 1, 2000.

CIDE. II Encuesta nacional a los actores del sistema educativo 2000. Chile, mayo 2001.

EZPELETA, J. Reforma educativa y zonas de turbulencia. México: Cinvestav, 1997.

GERSHBERG, A. I. Education “descentralization” processes. Mexico and Nicaragua: Legislativa versus ministery-led reform strategies. Comparative Education Review, Chicago, v. 35, n. 1, 1999.

GÓMEZ, R. C. Las condiciones del trabajo docente en la llamada postmodernidad. Disponível em: <http://www.netfirms.com>. Acesso em: 2001.

GONZÁLEZ, P. Financiamiento de la educación: una inversión creciente. Revista de Educación, Mineduc: Santiago de Chile, n. 291, 2001.

JIMENEZ, L. Los juegos de la reforma y la constitución de la profesionalidad docente. Sinéctica, México: Torreón, Coahuilla, n. 17, jul./dic. 2000.

LATAPI SARRE, P.; ULLOA HERRERO, M. El financiamiento de la educación básica en el marco del federalismo. México: Fondo de Cultura Económica, 2000.

LOYO, A. (Coord.). Los actores sociales y la educación. Los sentidos del cambio (19881994). México: Instituto de Investigaciones Sociales de la Unam, Plaza y Valdés Editora, 1997.

LUGO, F. R. R. La descentralización político-administrativa en México: el caso de la educación básica y normal (1992-1999). México: Faculdade de Ciências Políticas e Sociais, Unam, 2002.

MARIN, J. P. La reforma educacional chilena. Revista da Cepal, n. 73, abr. 2001.

MINEDUC. Estadísticas de la Educación. Año 2001. Santiago, Chile. 2001.

MIZALA, A. Sistemas de incentivos en educación y la experiência del SNED en Chile. Serie Economia, Santiago, n. 82, mayo/jun. 2000.

NARCISO, P. B. Pariente pobre de las estratégias educativas: todo para el pueblo, pero sin el pueblo. Santiago, Chile, 1997. Dissertação (Mestrado) - Universidad de Humanismo Cristiano.

NAVARRO, L. La autoevaluación como herramienta para el control y mejoramento de la gestión de los estabelecimentos municipales de educación. Santiago, Chile, 2000. Tese (Doutorado) - Pontificia Universidad Católica de Chile. 
NÚÑEZ, I. P. Modernizaciones en la educación chilena en siglo XX. 1994. Mimeog. . La política educacional del regimen militar, Chile. 1999. Mimeog. . Un siglo corto, reformas y revoluciones en Educación. 2002. Mimeog.

ORNELAS, C. El sistema educativo mexicano. La transición de fin de siglo. México: Fondo de Cultura Económica, 1995.

PARDO, M. C. (Coord.). Federalización e innovación educativa en México. México:El Colegio de México, 1999.

TAPIA, F. M. Descentralización y calidad de los aprendizajes en escuelas municipales chilenas. Santiago, Chile: Faculdad de Educación, Pontificia Universidad Católica de Chile, 1999.

TATTO, M. T. Education reform and state power in México: Paradoxes of decentralization. Comparative Education Review, Chicago, v. 43, n. 3, ago. 1999.

ULLOA, M. El financiamiento de la educación en la administración del presidente Ernesto Zedillo 1995-1998 y el proyecto de presupuesto de egresos para 1999. Relatório de pesquisa. México. 2000. Mimeog.

VILLEGAS, C P. Descentralización de la adminitración publica. El processo de municipalización democratica del sistema educacional chileno. Santiago, Chile: Universidad de Humanismo Cristiano, 1999.

YEPES, L. D. C. Políticas de educación para grupos vulnerables e lecciones de la experiencia chilena. Santiago, Chile, 2000. Tese (Mestrado) - Faculdad de Ciências Físicas y Matemáticas, Universidad de Chile.

Texto recebido em 10 ago. 2003

Texto aprovado em 03 out. 2003 